\title{
SOBRE LA DEMOCRACIA Y UN LIBRO DE RAFAEL MONTORO
}

\author{
Rafael E. Tarragó*
}

RESUMEN: Las características de la democracia representativa hoy en día en países donde ésta se ha consolidado (Europa Occidental, Estados Unidos de América, Canadá, Costa Rica, Nueva Zelanda, Australia y Japón) son similares a los términos como se le define en Principios de educación moral y cívica (La Habana, 1902), texto del estadista cubano Rafael Montoro (1852-1933) en el cual éste la precisa y plantea un programa de enseñanza de las actitudes y comportamientos necesarios en el ciudadano para ponerla en práctica y lograr su consolidación. Aunque esta obra de Montoro está basada en nociones del Estado y los derechos y deberes del ciudadano desarrollados en 2000 años de cultura occidental, también refleja el comportamiento de su autor como político y su personalidad.

Palabras ClaVE: Democracia representativa, Educación cívica, Ética política, Sistemas políticos.

\section{INTRODUCCIÓN}

En la primera década del siglo XXI todo el mundo (con notables excepciones) habla de la democracia como el sistema político al cual aspira. Claro está, que si preguntamos a nuestros demócratas qué quieren decir con esta palabra puede ser que recibamos definiciones divergentes. Sin embargo, me atrevo a decir que si hacemos esa pregunta en países del Occidente de Europa, en Estados Unidos de América, en el Canadá y en Costa Rica encontraremos que consideran que una de las caracterís-

* Universidad de Minnesota, Minneápolis (r_tarr@tc.umn.edu). 
ticas de la democracia en un Estado es que los gobernantes son elegidos por los ciudadanos mayores de edad y que existe la posibilidad de cambiar a la persona que ejerce el poder ejecutivo y a los diversos representantes, de diferentes ideologías políticas, en las cámaras legislativas. Para que esto sea posible en una nación-Estado, una parte importante de su población, en todos los niveles económicos y sociales, tiene que estar dispuesta a aceptar la ley electoral (que su partido pierda), predispuesta a la tolerancia política (respetar a los otros en las opiniones que no se comparten o se detestan) y a considerarse responsables de sus acciones. Esta definición "moderna" de la democracia y de la mentalidad democrática se encuentra en un texto de 1902 escrito por el estadista cubano Rafael Montoro.

\section{LA DEMOCRACIA}

Es cierto que para que en un Estado los ciudadanos ejerzan los deberes y reclamen los derechos políticos propios de un régimen democrático es conveniente que tengan cierto nivel de educación formal y conciencia política. También es verdad que es difícil que un sistema de este tipo funcione de hecho en una sociedad donde unos pocos controlan los medios de producción, las finanzas y las propiedades inmuebles y donde una inmensa mayoría sufre desempleo y desnutrición y carece de acceso a la educación formal básica y a un mínimo de atención médica. Estas realidades prácticas han hecho pensar a algunos que la democracia se basa en la educación universal, la distribución de la riqueza y un sistema de atención médico gratuito. ${ }^{1}$ Sin embargo, se dice que esos logros sociales existían en la República Popular China en la administración del canciller Mao Zedong (1949-1976) y en la Unión de Repúblicas Socialistas Soviéticas durante el mandato de José Visaronovich

1 Véase Paul Estrade, José Martí: los fundamentos de la democracia en Latinoamérica, Madrid, Ediciones Doce Calles, 2000. 
Chugachvili (llamado Stalin) entre 1924 y 1953, pero no creo que haya quien considere democracias a esos regímenes autoritarios.

Aunque una relativa igualdad económico-social es importante para que este sistema político funcione en un Estado, es indispensable para ello una mentalidad creyente en que el bienestar propio se beneficia del bienestar de todos, respetuosa de los ideales y los mecanismos políticos representativos de la población en general y en un buen número de sus ciudadanos en todos los niveles sociales y económicos. ${ }^{2}$ Muchos estados con una relativa igualdad económico-social se han convertido en oligarquías, porque sus clases dirigentes han administrado el Estado en beneficio propio y sin respeto ninguno por los ideales y los mecanismos políticos representativos. En más de un caso, los abusos de esos dirigentes corrompidos han facilitado el establecimiento de autocracias con dirigentes carismáticos y demagógicos llevados al poder por el voto de las mayorías desilusionadas con el gobierno representativo. Muchas revoluciones y golpes de estado han tenido lugar en naciones relativamente igualitarias, como reacción a la corrupción administrativa o a la irresponsabilidad de las clases dirigentes del Estado.

\section{UN LIBRO DE RAFAEL MONTORO}

Teniendo en cuenta lo dicho hasta aquí podemos concluir que la formación de un Estado democrático es un proceso orgánico y no un proyecto voluntarista de apóstoles políticos o de clases sociales predestinadas. La complejidad de los factores necesarios para mantener un gobierno de este tipo, incluyendo la mentalidad de los ciudadanos y los mecanismos administrativos, son el tema y desarrollo de un libro desafortunadamente ignorado hoy en día, aunque escrito para ser usado como manual de instrucción en las escuelas de la República de Cuba en el mismo año en

2 Véase Francis Fukuyama, La confianza, Buenos Aires, Atlántida, 1996. 
que esta República fue establecida. Principios de educación moral y cívica (La Habana, La Moderna Poesía, 1902), escrito por Rafael Montoro, es un libro en apariencia inferior a lo que podía esperarse de un estadista e intelectual como su autor. Obra de síntesis equivalente a los antiguos manuales para la educación de los príncipes a fin de que fueran justos y responsables, en este caso para la formación de ciudadanos conscientes de sus deberes y de sus derechos. ${ }^{3}$ Aunque su estilo es paternalista (fue escrito para que maestros de escuela prepararan clases para niños y adolescentes) y se encuentran en él términos hoy considerados ofensivos, esta obra es digna de una lectura cuidadosa por aquellos interesados en el fortalecimiento de la sociedad civil y el estado de derecho. No porque en ella se encuentre una fórmula infalible para copiar, sino por los datos y observaciones que contiene y que hacen reflexionar sobre la relación entre lo privado y lo público en la sociedad y el Estado.

La primera parte de Principios de moral e instrucción cívica explica normas de moral que recuerdan la Ética y la Política de Aristóteles. En sus capítulos (que llama lecciones) comenta conceptos sobre las relaciones humanas, los sentimientos morales y la importancia de la religión para la vida política en términos que recuerdan a Santo Tomás de Aquino y también el utilitarismo de Juan Locke. ${ }^{4}$ Entre los sentimientos morales importantes para la formación de una nación próspera y libre, Montoro incluye la laboriosidad y la tolerancia. En la lección segunda describe esta última como el respeto a todas las opiniones y creencias y aun a todo proceder dentro de la ley, y la llama indispensable en los pueblos que aspiran a ser libres, "pues donde ella falta sólo son posibles la tiranía o la anarquía." Sabiamente comprende Montoro, y enseña en

${ }^{3}$ Rafael E. Tarragó, "From the Education of the King to the Education of the Citizen: Manuals of Political Behavior in the Spanish Speaking World", Bulletin of Hispanic Studies, vol. 77, núm. 1, Liverpool, enero, 2000, pp. 61-62.

${ }^{4}$ Rafael Montoro, Principios de moral e instrucción cívica, La Habana, La Moderna Poesía, 1902, pp. 17-60. 
este libro, que un ser amante de la libertad no solamente lucha por su derecho a pensar y actuar libremente, sino también deja pensar y actuar libremente a otros, aunque no le guste lo que esos "otros" piensen o hagan. Manera de pensar esencial en un Estado democrático donde es preciso respetar el resultado de las elecciones aunque éste nos disguste y que contrasta con la manera de opinar de otros pensadores hispanoamericanos. ${ }^{5}$

Cinco de las ocho lecciones sobre principios de moral en este libro tienen que ver con los deberes del ciudadano. Pero no es Montoro un idealista kantiano que sólo ve el valor del cumplimiento del deber en sí mismo, sino un pragmático que estima que acatar los ciudadanos sus obligaciones redunda en su beneficio, ya que al efectuar sus deberes resulta en la preservación de la sociedad. No considera esto como un sacrificio en aras de la Patria, sino sensatas inversiones para beneficio propio y de los demás. Es muy perspicaz la lección cinco, sobre las obligaciones y derechos del niño, porque en ella menciona la importancia de aprender desde la niñez el gobierno (control) de sí mismo, como un hábito para la estabilidad y la libertad en una república. Viene al caso mencionar que Diego Saavedra Fajardo dice en su tratado Empresas políticas, publicado en 1640 y escrito para la educación del príncipe de Asturias Baltasar Carlos, que "la buena educación es necesaria en los príncipes porque ¿qué será pues un príncipe mal educado y armado con el poder?" En nuestra época de gobierno popular la educación de los ciudadanos en virtudes como el control de sí es igualmente importante, porque es esencial que éstos sepan controlar sus pasiones y sus entusiasmos, ya que solamente individuos que saben controlar sus inclinaciones violentas y desordenadas aceptarán derrotas en elecciones y solamente aquellos que no se dejan llevar por sus entusiasmos tendrán el

5 Julio Ramos, Divergent Modernities. Culture and Politics in Nineteenth Century Latin America, Durham, Duke University Press, 2001, p. 253.

${ }^{6}$ Diego Saavedra Fajardo, Empresas políticas, Barcelona, Planeta, 1988, pp. 23-30. 
sentido común para no presumir que el ganarlas quiere decir que pueden hacer todo lo que a ellos y a sus correligionarios políticos les venga en gana.

La segunda parte de Principios de moral e instrucción cívica explica sistemas políticos y económicos, así como procesos de gobierno y organización política. ${ }^{7}$ En la lección siete, sobre los partidos políticos, dice: "Debe trabajar cada partido por el predominio de sus ideas [...] pero sin desconocer ni olvidar que éstas no pueden agotar la idea del estado, ni satisfacer sus fines todos." En otras palabras, que ningún partido político puede con razón presumir de ser partido único y negarle la existencia legal a los que disienten de él, porque la Patria es de todos. No fue dogmático Montoro en sus apreciaciones sobre los fines y medios del Estado. En la lección número seis define las funciones esenciales del Estado en términos de acuerdo con lo que se llama "pensamiento liberal" - es decir, un Estado que provee solamente los servicios sin los cuales no podría subsistir ninguna sociedad civilizada tal como la administración de justicia, policía, etc.- - pero también considera (según la cultura y las necesidades de cada país) que hay legítimos fines facultativos del Estado, en los que la iniciativa privada no sea todavía fuerte para hacerse cargo de ciertos servicios. En la lección número 20, sobre el derecho del sufragio, Montoro llama al derecho de representación un derecho natural y condena la corrupción electoral como uno de los mayores males de la política. Claramente indica que ésta desestabiliza al gobierno representativo, no solamente porque le permite al rico y al poderoso imponer sus intereses y su dominio, sino también porque atrae hacia éste la desilusión en aquellos que ven sus derechos políticos frustrados y el desdén de los que venden sus votos o practican el fraude.

Entre las lecciones relacionadas específicamente con Cuba resaltan las número 11 y 12, en las que trata sobre la evolución política en la Isla (en donde desmiente con documentación la leyenda de que en el tiempo

\footnotetext{
7 Montoro, Principios, pp. 63-320.
} 
de España nunca tuvieron los cubanos la más mínima oportunidad de gobernarse en ningún nivel, leyenda difundida por los separatistas que se adjudicaron el crédito de ser los primeros en darle representación política al cubano y a los anexionistas, que negaban la capacidad para gobernarse a aquellos que no tenían sangre o costumbres anglosajonas) y la número 31, relacionada con el régimen municipal, la cual ofrece un resumen de la historia del municipio en Cuba, en el que resalta a éste como la institución más antigua y arraigada de la Isla, ya que sus atribuciones favorecieron un gobierno propio local de hecho hasta que las llamadas reformas ilustradas del rey Carlos III ( 1759-1788) comenzaron el proceso de centralización que culminó, a mediados del siglo XIX, con el sistema despótico de gobernadores con poderes omnímodos (1825-1878), lo que provocó la primera guerra de independencia cubana en 1868. Al terminar esta guerra en 1878 se limitaron las facultades del gobernador general, se formaron partidos políticos, los cubanos obtuvieron representación política y enviaron diputados al Parlamento (Cortes) en Madrid de 1879 hasta el fin de la unión de Cuba con España, el $1^{\circ}$ de enero de $1899 .^{8}$

Principios de moral e instrucción cívica concluye con nueve apéndices. El apéndice ocho es un análisis del comunismo, el socialismo y el colectivismo. No sorprende que Montoro considere al comunismo una locura, pero sí su reconocimiento de lo destructivo de las "frías intransigencias del individualismo." Opina que entre los extremos del individualismo y el colectivismo, lo más sensato es la solidaridad económica y social que se desarrolla con las inspiraciones de la fraternidad y la justicia. Recientemente Guillermo O'Donnell ha discutido las realidades asociadas con la reestructuración económica de los países de América Latina durante los años noventa en términos parecidos. ${ }^{9}$

${ }^{8}$ Hugh Thomas, Cuba or the Pursuit of Freedom, Nueva York, Harper \& Row, 1971, pp. 412-413.

9 Guillermo O’Donnell, "Ciencias sociales en América Latina. Mirando hacia el pasado y atisbando el futuro", LASA Forum, vol. 34, núm. 1, primavera, 2003, p. 9. 
El primer apéndice de Principios de moral e instrucción cívica es un sumario de la historia política de Cuba que termina con las palabras: "Reconocido ya el Estado Nacional por todas las potencias y constituido plenamente (es decir, una vez Cuba libre e independiente) su gloria, su fuerza y su prosperidad deben ser ya el ideal y la aspiración suprema de todos los ciudadanos." Dentro del contexto de las convicciones y la vida política de Montoro esta oración significa un testimonio de su fe democrática, porque hasta el último momento del vínculo entre España y Cuba, Montoro sostuvo que esa unión era lo más sensato para Cuba. ${ }^{10}$ Con su aceptación de la fundación de la República de Cuba con una constitución redactada por la Asamblea Constituyente, elegida por un electorado cubano, Montoro ilustró con el ejemplo la lección número 29, donde enseña que es un deber obedecer las leyes del país.

Nacido en 1852 y fallecido en 1933, a Rafael Montoro le tocó vivir un tiempo largo y lleno de transformaciones. Cuando nació, Estados Unidos era una nación grande, pero atrasada en comparación con el Imperio británico y con el Imperio francés de Napoleón III. Cuando nació, las repúblicas estables del mundo podían contarse con los dedos de una mano, el sufragio universal masculino solamente existía de facto en Estados Unidos de América (y era más bien sufragio de varones blancos mayores de edad), las monarquías eran la norma y entre éstas las constitucionales eran una minoría. El socialismo era entonces una idea nueva, que algunos gobiernos creían poder erradicar por la fuerza y otros creían sobornable por medio de leyes protectoras a los trabajadores y con programas de bienestar social. A su muerte en La Habana, en 1933, Estados Unidos era ya el coloso que conocemos, el sufragio uni-

${ }^{10}$ Rafael E. Tarragó, "Un estadista cubano: Rafael Montoro (1852-1933) y su tiempo”, en Rafael Montoro, Discursos y escritos, Miami, Editorial Cubana, 2000, pp. XVIIXVIII. 
versal masculino era la norma en los estados con gobiernos representativos y las monarquías estables en el mundo podían contarse con los dedos de las manos. El socialismo colectivista (llamado usualmente "comunismo") era la fundación ideológica de lo que había sido el imperio de los zares rusos y se ofrecía como el paraíso de los trabajadores y la sociedad del futuro con el nombre de Unión de Repúblicas Socialistas Soviéticas.

En Cuba los cambios habían sido drásticos. Cuba ya no era una sociedad esclavista gobernada por un español con poderes de rey absoluto, con fuertes lazos con Europa y un vasto mercado mundial para sus productos. Muchos de los cambios positivos que habían tenido lugar en Cuba - como la abolición inmediata de la esclavitud en 1886, la libertad de prensa en 1890, el Estado de derecho, la formación de partidos políticos representativos, la abrogación de las leyes raciales segregacionistas y el sufragio universal masculino no limitado a los blancos (proclamado y puesto en práctica por el gobierno autonómico que administró a Cuba de enero a agosto de 1898 — fueron propiciados por Montoro y sus colegas del Partido Liberal Autonomista Cubano.

Rafael Montoro nació en La Habana el 24 de octubre de 1852 dentro de una familia acomodada. Por razones de salud fue a estudiar al extranjero durante su adolescencia, pero retornó a Cuba y allí terminó sus estudios de segunda enseñanza. Volvió a salir de su patria otra vez por razones de salud y le sorprendió en España la primera guerra de independencia cubana en 1868. Cuando esta Guerra de los Diez Años terminó en 1878 regresó a Cuba para nunca más abandonarla. En 1879 Cuba obtuvo representación en las Cortes (Parlamento) de Madrid, al ser considerada Provincia de Ultramar, después del pacto del gobierno con los insurrectos cubanos en 1878, conocido como el Pacto del Zanjón, y en 1880 se decretó la abolición gradual de la esclavitud en diez años. Varios reformistas y separatistas dispuestos a ensayar la vía legal para obtener la libertad de Cuba formaron el Partido Liberal, que luego se llamó Partido Liberal Autonomista. Montoro entró en el PLA y fue elegido diputado varias veces. Como diputado en el Parlamento de Madrid trabajó por la abolición inmediata de la esclavitud con el concurso del veterano abo- 
licionista cubano en España Rafael María de Labra y con su colega cubano Miguel Figueroa. También propuso la liberalización del sistema arancelario en Cuba y la aplicación en la Isla de libertades civiles existentes en España desde la implementación de la Constitución de 1876 (como la libertad de expresión, de asociación de prensa y de religión y el matrimonio civil). Todas esas propuestas eran ya realidad en Cuba en 1895.

Algunos historiadores ven en los autonomistas solamente aquellos que prefirieron buscar las libertades políticas por la vía pacífica y se opusieron a la guerra en $1895 .{ }^{11}$ Pero otros tienen diferente opinión y una historiadora cubana ha escrito que no debe de ser ignorado que aunque los autonomistas no constituyeron la vanguardia patriótica cubana, tampoco fueron asimilistas y existió en muchos de ellos un fuerte sentimiento de cubanía. ${ }^{12}$ Si juzgamos por lo que los dirigentes autonomistas escribieron e hicieron, éstos eran nacionalistas, distinguiendo una cubanidad dentro de la nación española, salida de ésta, pero con personalidad propia. Rafael Montoro no veía a España como la nación que con la espada en una mano y el cirial en la otra había traído a América el despotismo y la superstición, sino la tierra de donde procedían los antecesores de los criollos cubanos, y una nación que en el pasado se había distinguido por sus libertades y no por el despotismo que luego en ella surgió y proponía que se buscase la genuina tradición de España no en los errores, injusticias y torpezas que viciaron su legislación, sino en los altos ideales y concepciones que presidieron sus grandes obras. ${ }^{13}$

${ }^{11}$ Paul Estrade, "El autonomismo criollo y la nación cubana (antes y después del 98)", en Consuelo Naranjo Orovio y Carlos Serrano [eds.], Imágenes e imaginarios en el ultramar español, Madrid, CSIC, 1999, pp. 168-169.

12 Véase Luis Miguel García Mora, "Del Zanjón a Baire. A propósito de un balance historiográfico sobre el autonomismo cubano", en José Opatrny [ed.], Cuba. Algunos problemas de su historia, Praga, Universidad Carolingia, 1995, pp. 29-45; María del Carmen Barcia Zequeira, Una sociedad en crisis: La Habana a finales del siglo XIX, La Habana, Editorial de Ciencias Sociales, 2000, p. 52.

${ }^{13}$ Rafael Montoro, "Conferencia pronunciada en el Ateneo de Madrid el año 1894”, en Rafael Montoro, Discursos y escritos, p. 102. 
A pesar de ver en la nacionalidad española la fundación de la cubana, el nacionalismo de los autonomistas no era racista. Así como la Constitución española de 1876 consideraba español a todo aquel nacido en su territorio, los autonomistas consideraban cubanos a todos aquellos nacidos en Cuba. Francisco Augusto Conte no veía razón ni motivo para temer al negro ni recelar de su actitud cuando gozase de todos los derechos políticos. Todo lo contrario, veía en el afrocubano un elemento de la población con el cual los autonomistas tenían que contar. ${ }^{14}$ Eliseo Giberga tampoco veía una amenaza en los afrocubanos, sino que creía que en ellos debían fijar su atención políticos y gobernantes, en Cuba estaban y cubanos eran. ${ }^{15}$ Rafael María de Labra fue abolicionista infatigable, y una vez declarada en Cuba la abolición plena de la esclavitud en 1886 luchó por el sufragio universal masculino, el cual le daría el voto a todo ciudadano español mayor de edad, blanco o negro. ${ }^{16}$ Por su "inclusivismo" en la praxis autonomista después de 1890, el dirigente afrocubano don Martín Morúa Delgado decía en 1892 en su periódico La Nueva Era que "el pueblo afrocubano no tenía otra opción sino unirse al partido autonomista, el partido de los cubanos." 17 En 1893 hubo un enfrentamiento entre los autonomistas afrocubanos y los otros en la región de Santiago de Cuba, cuando los primeros demandaron la mitad del número de diputados a Cortes, diputados provinciales, consejales y la mitad de los empleados en las oficinas de administración pública, situación que se resolvió cuando la directiva del PLA hizo algunas concesiones a los afrocubanos. ${ }^{18}$

${ }^{14}$ Francisco A. Conte, Las aspiraciones del Partido Liberal de Cuba, La Habana, Imprenta de A. Álvarez y Compañía, 1892, p. 197.

${ }^{15}$ Eliseo Giberga, "Apuntes sobre la cuestión de Cuba por un autonomista", en Obras, La Habana, Imp. y Papelería de Rambla, Bouza y Cía., 1931, vol. 3, p. 113.

16 Véase Rafael María de Labra, El sufragio universal en las Antillas Españolas, Madrid, 1890.

${ }^{17}$ Martín Morúa Delgado, "Factores sociales", en Obras completas, La Habana, Publicaciones de la Comisión Nacional del Centenario de don Martín Morúa Delgado, 1957, vol. 3, pp. 233-234.

18 Oilda Hevia Lanier, El Directorio Central de las sociedades negras de Cuba (18861894), La Habana, Editorial de Ciencias Sociales, 1996, pp. 48-49. 
De los escritos de Conte, Giberga y Labra se desprende que ya en el último cuarto del siglo XIX había en Cuba asociaciones cívicas conscientes de conceptos modernos sobre los derechos políticos de los ciudadanos, que incluían a cubanos de ascendencia africana. Esto ha sido confirmado por estudios sobre las llamadas Sociedades de la Raza de Color que florecieron entre 1878 y $1895 .{ }^{19}$ Los autonomistas cubanos creían que los derechos civiles y políticos y el gobierno representativo no eran cosas de anglosajones, sino una aspiración común a pueblos diversos. Aunque reconocían la importancia del mercado de Estados Unidos para la industria azucarera en Cuba, no creían en la necesidad de depender de él perennemente. Rafael Montoro criticó el llamado tratado de reciprocidad Foster Canovas, firmado entre España y Estados Unidos en 1891, por considerarlo ventajoso en demasía para éste. ${ }^{20}$ Francisco Augusto Conte rechazó la anexión de Cuba a Estados Unidos como medio para obtener libertades políticas y económicas en la Isla, porque para él liberalizarse no era sinónimo de americanizarse. ${ }^{21}$ En su conferencia "El pesimismo en la política cubana" (La Habana, 1887), Eliseo Giberga hizo referencia al progreso en la vida política cubana del siglo XIX, al destacar la notoria diferencia entre el gobierno con una constitución y representación en el parlamento de Madrid después de 1878, y el régimen de gobernadores generales con poderes de reyes absolutos existente entre 1825 y $1878 .{ }^{22}$ Para 1891 , diez años después de su funda-

19 Véase Philip Howard, Changing History. Afro Cuban Cabildos and Societies of Color in the Nineteenth Century, Baton Rouge, Louisiana State University Press, 1998; Carmen Victoria Montejo Arrechea, Sociedades de instrucción y recreo de pardos y morenos que existieron en Cuba colonial. Periodo 1878-1898, Veracruz, Centro de Estudios del Caribe del Instituto Veracruzano de Cultura, 1993.

${ }^{20}$ Montoro, "Comité Central de Propaganda Económica (Crítica del Convenio de reciprocidad comercial con los Estados Unidos”, en Rafael Montoro, Discursos y escritos, pp. 413-414.

${ }^{21}$ Conte, Las aspiraciones del Partido Liberal, pp. 150-153.

${ }^{22}$ Véase Eliseo Giberga, El pesimismo en la política cubana, La Habana, Imprenta "El Retiro," 1887. 
ción, el Partido Liberal Autonomista cubano no había obtenido la autonomía para Cuba y las leyes electorales parciales a los españoles peninsulares continuaban en vigor a pesar de sus protestas: pero gracias a sus esfuerzos, en esos años la Constitución de 1876 fue puesta en práctica en la Isla, así como los derechos de expresión, prensa y asociación, el matrimonio civil, y la reforma de la legislación civil y penal. La libertad de expresar en la prensa opiniones políticas contrarias al sistema de gobierno se logró en Cuba en 1891 tras la apelación del dirigente independentista don Juan Gualberto Gómez al Tribunal Supremo de Madrid, con la asistencia del diputado autonomista Rafael María de Labra. ${ }^{23}$

La decisión tomada por Rafael Montoro en 1895 de no seguir la rebelión separatista se comprende al leer su discurso "Explicación de motivos al votarse la ley descentralizadora Abarzuza en febrero de 1895," porque al obtenerse una reforma tan amplia sin derramamiento de sangre y después de tantos años tratando de lograr algo similar, era lógico que actuase como lo hizo. Su continua lealtad a la Corona española, aun después del arribo a Cuba del destacado general Weyler, en febrero de 1896, como gobernador general, con amplios poderes para reprimir la rebelión y sin orden de aplicar la Ley Abarzuza — cuando otros autonomistas, como don Martín Morúa Delgado, se sumaron al movimiento separatista — ha sido muy criticada. Muchas razones pudo tener un civil nato como Montoro para no integrarse a un movimiento claramente dirigido (después de la muerte de José Martí el 19 de mayo de 1895) por militares. La Corona española podía llevarse a Weyler (y se lo llevó), pero a un caudillo cubano, ¿quién se lo llevaría si no otro caudillo?

Cuando la Corona española le concedió la autonomía a Cuba a finales de 1897 se creía que con esto se evitaría la intervención de Estados Unidos en Cuba. Rafael Montoro, quien deseaba una Cuba como la soñó José Antonio Saco, “no sólo rica, ilustrada (moderna), moral y po-

${ }^{23}$ Emilio Roig de Leuchsenring, "Juan Gualberto Gómez, paladín de la independencia y la libertad de Cuba”, en Juan Gualberto Gómez, Por Cuba Libre, La Habana, Municipio de La Habana, Oficina del Historiador de la Ciudad, 1954, p. 45. 
derosa, sino que fuese también cubana y no angloamericana," vio la autonomía bajo España como un paso a la autodeterminación y aceptó la Secretaría de Hacienda en el gabinete del gobierno autonómico cubano establecido en Cuba el $1^{\circ}$ de enero de 1898. En abril de ese año hubo elecciones en Cuba con amplia representación, porque junto con la autonomía se estableció el sufragio universal masculino sin trabas raciales. El gobierno autonómico funcionó durante la guerra entre España y Estados Unidos y ahí están sus actas y documentos de su administración para demostrarlo. Nunca sabremos si hubiera fracasado, porque al ganar Estados Unidos su guerra contra España, Cuba, Filipinas, Guam y Puerto Rico pasaron a manos de éste y la soberanía de la Corona española y toda su administración (incluyendo los gobiernos autonómicos de Cuba y Puerto Rico) cesaron el $1^{\circ}$ de enero de 1899.

\section{CONCLUSIONES}

Este artículo trata sobre la democracia moderna (o al menos una definición extendida en buena parte de los países — repúblicas y reinos-que hoy en día se autodefinen como democráticos) y un texto de Rafael Montoro que no está relacionado con el autonomismo en la Cuba española, pero creo que cuando se conoce la labor legislativa y la lucha contra la corrupción administrativa en la Isla del Partido Liberal Autonomista y la actividad política de Rafael Montoro entre 1878 y 1898 en la oposición marginada, se comprende que mucho de lo que éste dice en su libro Principios de moral e instrucción cívica es fruto de la experiencia y reflejo de una personalidad íntegra, pero consciente de que cada hora en la vida tiene sus posibilidades y que la política es el arte de ajustarse a ellas.

A finales de 1898, el último gobernador español de Cuba fue a despedirse de Montoro y le propuso que se fuera a España. Éste rehusó su propuesta y se quedó en Cuba, aceptando el proyecto de los que habían sido sus adversarios políticos y cooperó con el gobierno de la República 
de Cuba cuantas veces se le pidió su asistencia profesional en proyectos dignos. Dos presidentes ex combatientes en el Ejército Libertador de Cuba le confirieron su confianza — José Miguel Gómez enviándole como representante de Cuba a Inglaterra, y Mario García Menocal haciéndole ministro en sus dos gabinetes. En mayo de 1913 don Juan Gualberto Gómez escribió una carta dirigida a los que se oponían a la participación de Montoro en un gobierno republicano porque había sido fiel a la Corona española y militante del Partido Liberal Autonomista, en ella expuso que "los valores éticos, la impecable buena fe, la honorabilidad sin tacha conque Montoro mantuvo su ideario liberal" eran garantías de que con honor y limpieza habría de desempeñar cargos públicos en la República. ${ }^{24}$ Con José Antonio González Lanusa representó a Cuba en la Tercera Conferencia Pan-Americana. Su casa en La Habana se convirtió en centro de reunión de intelectuales y jóvenes de diversas opiniones políticas, como Manuel Sanguily y Enrique José Varona. ${ }^{25}$ En 1931 prestó su casa para una reunión entre ministros del gobierno y disidentes opuestos a las ambiciones dictatoriales del presidente Gerardo Machado (ex general del Ejército Libertador Cubano). ${ }^{26}$ Cuando falleció, el 12 de agosto de 1933, Montoro era considerado un prócer de su patria.

Principios de moral e instrucción cívica es un compendio de principios de ética e instrucción política, erudito y práctico a la vez, porque su contenido refleja no solamente los conocimientos históricos y legales de Rafael Montoro, sino también su experiencia como diputado cubano en el Parlamento de Madrid y como ministro de Hacienda del Gobierno Autonómico de Cuba. Su estilo es apropiado para un manual de ciudadanos libres, porque ni se pone de ejemplo ni sugiere que las lecciones

${ }^{24}$ Lilia Castro de Morales, “D. Rafael Montoro y su aporte a la cultura cubana”, en José Barriel Domínguez, Bibliografía de Rafael Montoro y Valdés, La Habana, Biblioteca Nacional, 1952, p. 4.

${ }^{25}$ César García Pons, "Rafael Montoro y sus ideas políticas", Bohemia, 20 de julio de 1952, pp. 20-22 +111-112.

${ }^{26}$ Cosme de la Torriente, Juan Gualberto Gómez, La Habana, Academia de la Historia de Cuba, 1954, p. 30. 
que expone sean fórmulas infalibles. Explica principios de ética formados en más de 2000 años de cultura occidental aceptados por la mayor parte de los estados modernos como normativos, y principios de gobierno representativo considerados como la aspiración de un pueblo libre en su tiempo y hoy en día, para ser seguidos por su propio valor. Es evidente que para Montoro, el maestro, explica los deberes y derechos del ciudadano, no los inventa.

Debido a su publicación cuando Cuba salía de la dominación directa de Estados Unidos de América, es posible ver este libro de Montoro como una respuesta al anglosajonismo de los angloamericanos en Cuba, que consideraban a los cubanos como ignorantes y sin concepto ninguno sobre las libertades políticas modernas por ser descendientes de españoles o de africanos (o una mezcla de ambos), naciones que estimaban muy por debajo en su escala de capacitación para gobernarse. También puede haber sido motivado por el escepticismo de Montoro sobre las condiciones del pueblo cubano (tanto blancos como negros y mulatos) para gobernarse. En mi opinión, Montoro pensaba que cierto tipo de entrenamiento o educación es esencial para que un individuo pueda desempeñar bien un oficio o una profesión y que en un pueblo donde el sufragio universal masculino le daba participación en el gobierno a todo varón mayor de edad, un mínimo de educación política era esencial para que éstos pudieran ejercer bien sus obligaciones políticas como ciudadanos. En su artículo de 1918 "La educación popular," citando a Adam Smith dice: "Si se deja a la muchedumbre sin instrucción, será fácil juguete de los demagogos." 27

Teniendo en consideración la importancia de una mentalidad receptiva a los ideales democráticos para la consolidación y la preservación de un gobierno democrático, Principios de moral e instrucción cívica merece ser leído hoy en día, porque no ha dejado de tener valor para la educación de ciudadanos cien años después de su publicación, apelando

${ }^{27}$ Montoro, “La educacion popular”, en Discursos y escritos, p. 156. 
a la inteligencia del pueblo para informarlo e inspirarlo, no a sus emociones para agitarlo y acaudillarlo. En Hispanoamérica hemos sufrido por el personalismo de los fundadores de nuestras repúblicas, imitado por los dirigentes políticos que les han sucedido, y por la idealización de la violencia de éstos, que la consideraron necesaria para obtener la libertad. Mucho y diverso se ha escrito sobre la lucha por la libertad en América Latina, pero poco sobre cómo usar ésta sensatamente. La salida del círculo vicioso de fluctuación entre tiranía y anarquía, prosperidad dependiente y miseria autárquica, no está en inmolarse en aras de la Patria ni en visiones utópicas (irrealizables por definición) sino en la adopción por todos los ciudadanos de una ética de sentido común, según la cual los deberes tienen beneficios y los derechos límites prácticos. Una mentalidad guiada por estos principios es esencial en los ciudadanos de un Estado democrático. Rafael Montoro fue uno de los pocos en Nuestra América que predicó con sus palabras y sus hechos el uso sensato de la libertad en la vida civil y la importancia de cumplir los deberes que ser un ciudadano en una nación de hombres y mujeres libres conlleva. ${ }^{28}$

${ }^{28}$ El texto de su manual de ciudadanos se encuentra en la Red en la dirección (http://libtext.library.wisc.edu/IbrAmerTxt/). 